\title{
The status quo and development trend of smart water research
}

\author{
Zhu Zhaohui ${ }^{1}$, Liu Ning ${ }^{2}$,Li Xiuwen ${ }^{1, \mathrm{a}}$,Yuan Zhaowei $^{2}$,Wang Guochuan ${ }^{3}$ \\ ${ }^{1}$ China Institute of Water Resources and Hydropower Research, 100038 ,Beijing,China; \\ ${ }^{2}$ Datang (Beijing) Water Engineering Technology Co., Ltd, 100033 ,Beijing,China \\ ${ }^{3}$ Taiping Bay Power Plant,118000,Dandong,China.
}

\begin{abstract}
Smart Water uses sensor equipment to sense natural water and social water circulation system, to achieve real-time monitoring and dynamic collection, scheduling and remote management of water information through Internet of Things, and to realize the deep processing of multi-source heterogeneous data through the data mining and multi-dimensional analysis of the information system, which provides an important reference for the intelligent management and decision-making of urban water affairs. With the continuous innovation of information technology such as big data and cloud computing, smart water development has ushered in new opportunities. This paper mainly summarizes the status quo of smart water research at home and abroad from the perspective of application practice, and analyzes the main problems facing the development of smart water in China. the development trend of smart water is proposed according to the current technological development and industry needs.
\end{abstract}

\section{Introduction}

In 2009, IBM proposed the concept of "Intelligent Earth", which is intended to fully utilize the new generation of IT technology in all walks of life. In other words, embedding and equipping sensors into various objects in every corner of the globe such as hospitals, power grids, railways, buildings, water systems, dams and oil and gas pipelines. The "Internet of Things" is formed through interconnection, and then the Internet of Things is integrated by supercomputers and cloud computing, which can eventually form "Internet + Internet of Things = Intelligent Earth " [1 2]. Under the background of current intelligent cities, water conservancy modernization, strictest water resources management and ecological civilization construction, China has gradually moved toward the development of smart water resources with high technology content in the comprehensive management of water resources [3]. In December 2016, the Ministry of Water Resources issued the "Guiding Opinions on Further Strengthening the Construction and Management of Water Conservancy Informatization" to promote the transformation of "Digital Water Conservancy" to "Smart water Conservancy" and promote the modernization of water management system and water treatment capacity.

Smart water System is a complex large-scale system project that uses automated equipment to acquire underlying data and combines information technology to extract, process and disclose urban water information, thereby efficiently managing urban water supply and drainage, sewage treatment and reclaimed water comprehensive utilization and other processes [4]. The biggest difference between smart water conservancy management and digital water conservancy management is that smart water conservancy management is not only based on existing monitoring data for post-processing and analysis, but also based on existing monitoring data, combined with intelligent analysis theory and method to propose predictive or predictive advice or judgment. At present, the construction of smart water at home and abroad is in full swing. China's water conservancy system is gradually moving towards a data-based, programmatic analysis, humanized application and industrial value-added [6]. This paper summarizes the main research ideas and practical results of the current smart water affairs, analyzes the main problems faced by China's smart water system development, and proposes the development trend of smart water services according to the current technology and industry development direction.

\section{Overview of Smart water Research}

\subsection{Current status of foreign smart water research}

In May 2009, the "Smart water Initiative", a foundation of the private organization "Water Innovation Alliance", took the lead in presenting the concept of smart water. In recent years, many countries have carried out research and practice of smart water to varying degrees.

As an industry leader, IBM has carried out multi-faceted research on smart water system, which is characterized by automation, interactivity and 
intelligence. IBM's smart water resources management realizes intelligent transformation of water resources through data and system integration, intelligent analysis and collaborative processing, which cover water resources monitoring and protection, watershed water resources operation management, smart dam management, regional smart water resources allocation management, water management company integrated operation management, smart pipe network risk management, urban flood analysis and forecasting and emergency, urban sewage management and other fields [6]. IBM has made its smart water system more widely used. For example: (1) Through data analysis to achieve pre-maintenance and optimization process, it change passive response to active prediction and help the Columbia Water Authority to better utilize human resources and extend the life of existing equipment; (2) Through developing multi-organization data sharing, visualization pipe network and equipment (such as water tanks, wells, pressurized water stations, water towers, etc.) and information release functions, it can realize the smart water management system with real-time collection, timely discovery of problems, grooming of pipe network sequence, optimization of scheduling and sharing and promotion across departments collaborative, which helps the Sonoma region of California, USA, address water stress and water level fluctuations during peak water use [5].

In Japan, through monitoring terminals and monitoring systems, the Water Resources Management Departments can control water and water quality in real-time water supply plants, sewage treatment plants, and pipe network systems; using innovative technology such as Internet of Things, cloud computing, big data, and wearable devices, it can intelligently manage and maintain the water supply and drainage infrastructure. Hitachi's "information and control integration system" is used to manage the operation data of various water treatment facilities such as tap water, sewage, and water, to improve the overall water cycle management efficiency of the city [4 5].

Korean KICT experts are also working to promote regionalized smart water network construction. They believe that smart water network is a future-oriented water management technology. It can improve water resources production, supply and management efficiency through the integration of the latest information technology and communication technology with existing water resources management, and then solve the problem of regional imbalances in water resources [5]. The Korean government's u-Korea development strategy, which is committed to bringing Korea into the intelligent society ahead of time, has now entered the intelligent stage. In the smart water sector, the small-factory management system (u-FMS) based on wireless sensor networks can monitor the water supply in large cities in real time. System pipeline flow, water pressure and water quality, timely treatment of water leakage.

The smart water project carried out by French telecom operator Orange Group and French Water Company starts from the user's demand, starting from the point of development, and developing services according to the demand, from point to line to the whole industry. For example, its smart water meter business uses sensors to detect water quality, and sends the detection results to the data center for analysis, so that the analysis results are provided to users intelligently and in real time [7].

Specific to the technical level, most foreign smart water systems are composed of computer-aided (IT) and business technology support (OT). Strengthening IT-OT integration is the main work of foreign water divisions, and OT is the intelligent technology that provides water systems. Not only the collection of data, but also visualization and analysis. The development and application of foreign informatization, not only for the water system itself, also extends to the user's water consumption forecasting and analysis services. Foreign information application is earlier than domestic, especially the deep mining and analysis of data. Some water departments in the UK have paid attention to the analysis and application of production data in the early information construction. The establishment of hydraulic model is also developed earlier than China. Several hydraulic model software such as Infoworks, DHI, KYPIPE, and Bently, which are used by domestic water divisions, are all software from the United Kingdom, Denmark, or the United States [8].

\subsection{Current status of domestic smart water research}

The development of domestic smart water services has mainly experienced three stages of automation, informationization and intelligence. In 2013, at the 8th China International Conference on Urban Water Development and New Technology Equipment Expo held in Changsha, the Digital City Engineering Research Center of China Urban Science Research Association first proposed China's smart water concept. At present, many cities in China have carried out the construction of "Smart water" and have achieved certain results.

Based on production data center and GIS technology, Jiangyin smart water [9] realized various dynamics of water supply system including pressure, flow, water quality, water plant, pump station, secondary pressurized pump house, pipe network failure, personnel, alarm, etc. Deep integration of information and decision-making applications, the project also integrates real-time scheduling technology with international cutting-edge level, combined with advanced online model architecture and real-time data cleaning algorithms to achieve real-time model analysis and scheduling decision support, thus helping the water department to build advanced Comprehensive monitoring, warning, decision-making and command platform for urban water supply. The Singapore Smart water Network System [9] built by Chinese companies acquires online real-time hydraulic data by installing sensors on the pipe network, and provides a series of water network management tools to assist in the operation and management of pipe networks, including squibs, water quality event alarms, and leaks. Point positioning, the system's big data analysis engine includes a variety of algorithms and models, online 
hydraulic modeling, valve operation simulation and simulation, automatic partition model, water demand forecasting and load distribution, and GIS-based data visualization. Shanghai Zhabei District Smart water System [9] project integrates and cleans the basic data through data drafting, parameter estimation, interpolation and other algorithms. The big data cloud platform technology is used to monitor the online data in real time, and the abnormal problems are quickly detected and responded to the alarm reminder. China's energy-saving water conservancy production operation information system [10] obtains the working condition data collected by the PLC system from the production site automatic control network through the working condition data acquisition instrument, and transmits it to the system platform server through the data transmission middleware, and the data transmission middleware adopts data encryption technology, which can further reduce the risk of information loss. Using Huffman algorithm to compress data, can reduce the amount of data transmission, which only transmit new and changed data, minimize the amount of data transmitted. So, it can improve the concurrency and provide a good data caching mechanism, and through the resume of the breakpoint, the correct data does not lose, and it also ensures the reliable acquisition of the collected data.

Due to space limitations, this paper only lists four typical cases. From the perspective of logical architecture, China's smart water projects are mainly divided into sensing layer, network layer, support layer, application layer and presentation layer [11 13]. The specific functions of the layering are as follows:

(1) The sensing layer is the basis of the Internet of Things technology architecture, and is also the source of real-time production data; collecting water, water, flow, rainfall, meteorological and other wading data through data acquisition instruments, intelligent controllers, online detection instruments, and terminals. Realizing the sense of running status, location information, facility equipment ID, etc.; and providing multi-source data by automated control equipment and video linkage;

(2) The network layer is responsible for information transmission. Through the two main modes of wired transmission and wireless transmission, real-time dynamic collection, transmission and storage of the sensing layer information is realized by using optical fiber, GPRS, 4G, satellite, short wave and other transmission technologies to form a perfect network system;

(3) The support layer design space attribute database, production operation database, water basic database, water supply facility database, government information resource library, etc.; centralized processing, storage, transmission, exchange and management of water plant and pipe network information, production process data, production management data, safety monitoring data, and spatial geodetic data are stored in a unified manner to achieve data disaster preparedness management; and through the establishment of data warehouses, functional warehouses, workflows, etc., building a complete information resource management, integration, sharing and development. Utilizing the standard specification system and operation management system, build a complete information data system and technical support system; based on big data mining technology, it can mine many ordered or disordered data collections, and give full play to the value of the data itself;

(4) The application layer realizes the display of the distribution of the factory stations of the production enterprises and the production and operation process pictures of each factory through the sorting, processing and display of various types of data, and realizes the over-limit alarm for the real-time operation data of each factory; realizes information sharing, system upgrade and secondary development, segmentation of business processes, multi-network convergence, and it combined with data center big data applications to achieve the role of decision-making and unified business management;

(5) The presentation layer realizes the storage, analysis and processing of the water data and the data conversion between the network layer and the application layer, and is responsible for the management of the network equipment and the display of the business information and the device information. The service layer designs and implements a series of standard service interfaces based on the common needs of water users, and the portal system and mobile app established on this basis. Users can access various portals to obtain various water information services, query water usage, and the system also the water stop announcement, repair information, etc. can be pushed to the user; the reference model [14] is shown in Fig. 1. 


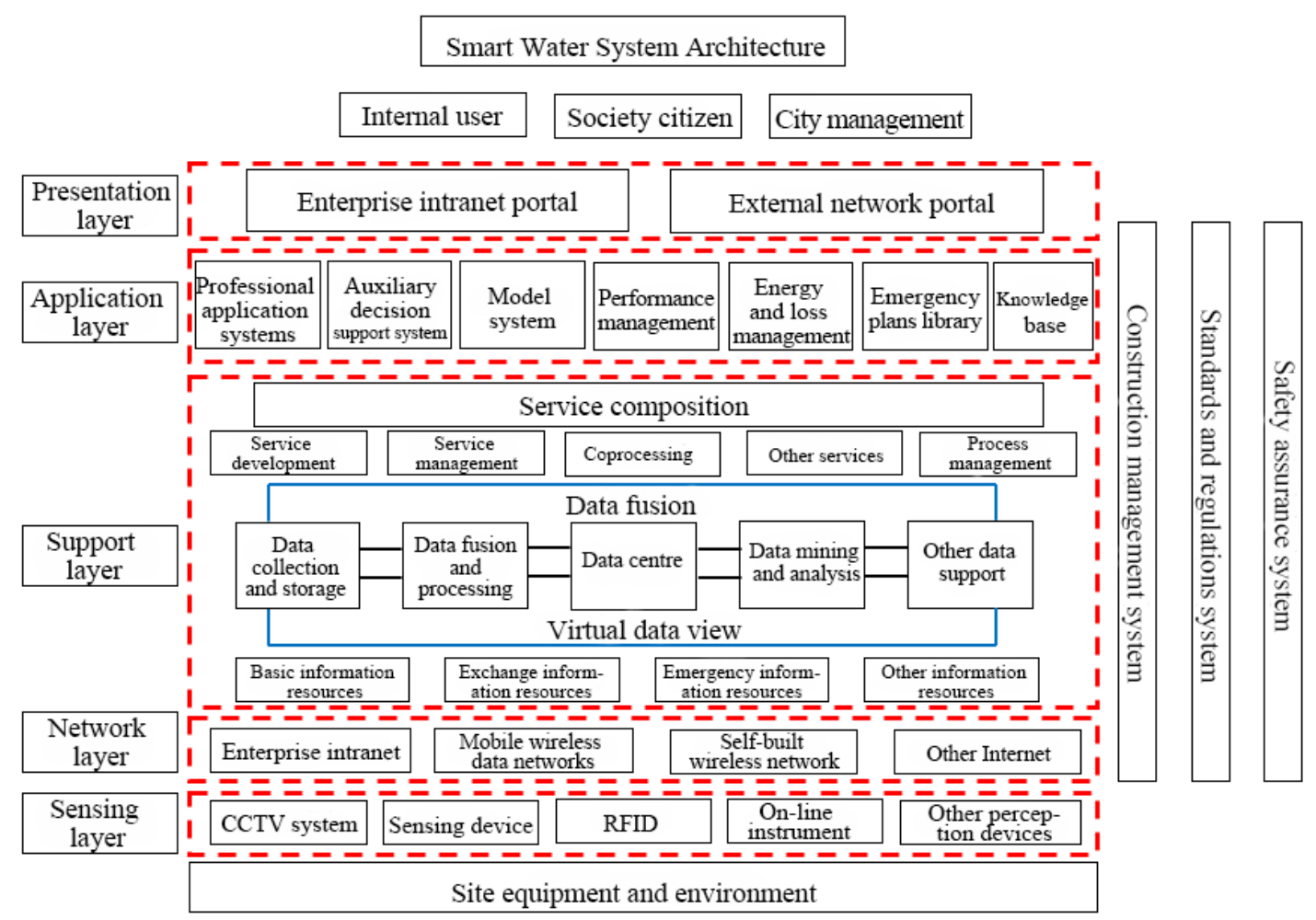

Fig.1 Reference model

\section{The main problem facing smart water}

Although the current domestic and international smart water construction is in a stage of rapid development, due to the lack of top-level design [14], etc., some problems have also appeared. The problem of China's smart water affairs is mainly reflected in policy constraints, lack of standard norms, prominent information islands, difficult data operations, and lack of professional talents [6].

(1) Policy system constraints

Under the current system, functions such as water supply, drainage, sewage treatment, sponge city, and black and odorous water body management are scattered in various administrative departments. The wading management system also has the phenomenon of dividing urban and rural areas and subdividing according to the data, which has slowed down the construction of smart water services. schedule. From the water source to the faucet, it is subject to the approval and management of several administrative departments, but the lead department of the main responsibility is missing. The standards of management rules of each supervisory unit are different, resulting in different standards for water information system construction and reducing the utilization rate of the system. At present, the relevant laws and regulations on smart water affairs have not been perfected. Even some local management methods or water supply regulations have problems of imperfect operation and even difficulty in law enforcement.

(2) Missing standard specifications

At present, there are few normative standards for smart water affairs. The Ministry of Housing and Urban-Rural Development has issued the "Guidelines for the Construction and Application of Smart water
Information System", and Zhejiang Province has issued the "Safety Technical Specification for Smart water Supply and Drainage Information GEN System" (DB/T2051-2017).). These specifications have milestones, but they are far from meeting the needs of the industry. In addition, due to differences in industry understanding, although there are currently provisions for the development of intelligent standards for pipe networks, water meters, customer service systems, etc., most of them are based on "water informationization". Domestic research on smart water system has not yet formed an independent scientific system.

(3) Serious problem of information island

According to the survey by the smart water Affairs Center of the China Eco-City Research Institute on 94 representative water companies that have developed smart water construction, $63.4 \%$ of the surveyed companies have proposed that the biggest bottleneck for Smart water construction lies in the technical barriers of different software vendors and the software. There are compatibility difficulties between systems. The effective operation of Smart water System is based on a wide range of water information resources, which are scattered among different entities, and the information interconnection is not good enough to limit and hinder higher-level intelligent applications. The water information system lacks integrity, and the business systems are isolated from each other. There is no stable information foundation in the vertical direction. There is no complementary information bridge in the horizontal direction. There are obstacles in communication, and the problem of information islands is prominent, forming an information barrier lake.

(4) Data operation difficulties

The greatest value of Smart water is its massive data operation. Whether the data is accurate and timely 
determines the application of the system to a large extent, including data analysis and decision making through data analysis mining. The data of smart water is multi-dimensionally collected. It is necessary to have strict considerations to fully understand whether the quality of the instrument is up to standard, whether the transmission is smooth, and whether data security is guaranteed. Basic data collection also needs to be systematically combed and feedback combined with the needs of the Smart water industry to collect key data that meets the needs. Limited by the current level of instrument manufacturing and operation and maintenance management, it needs to be further strengthened in this respect. The key to Smart water is the deep excavation of data. The depth of excavation determines the height and thickness of intelligent in the spatial three-dimensional structure. How to adopt a variety of data analysis methods, how to identify the data analysis model that meets the needs of water users is the key to improving the quality and value of the data. Although some of the current smart water services have certain computing and data mining capabilities, there is still a certain gap with expectations.

(5) Lack of professional talents

The core of smart water is how to optimize water operation management through the effective combination of software and hardware systems. The smart water system is generally commissioned by a professional software company, but the software only starts from the technical logic, and fails to start from the business logic. The cross-domain causes the difficulty of the later operation and maintenance communication, so that the value of the software system cannot be maximized. Therefore, in the process of smart water construction from the extensive development stage to the mature stage, with the professional classification of technology applications, effective construction of talent strategy echelon is crucial.

\section{Smart water development trends}

As the level of sensor manufacturing increases, the maturity of technologies such as the internet of Things and cloud computing, as well as the continuous improvement of management levels, will revolutionize water work in sensing and monitoring, transmission and computing, business applications and service models. Impact, the construction of smart water services will also be increasingly perfect. In the future, the development of smart water services will develop toward the trend of "a set of networks, a cloud, a picture, a library, and a platform".

"One set of network" is a computer wide area network that integrates multi-level and multiple management department network architectures. It is a dedicated network for all kinds of water information transmission, and it carries water resources production, water operation, water management, water consumption, and water service resource interoperability. system applications. "One cloud", the water data center cloud platform, integrates the water system infrastructure resources and establishes a "Smart water cloud" with practical problems for various types of production operations (such as blasting warning, leakage control, water volume), forecasting, etc. Research accurate and effective algorithms through data analysis to provide effective decision-making basis for water system platforms. "One map" refers to the water geographic information service platform, integrated engineering survey data, basic geographic data, and thematic attribute data. Based on GIS technology, a visual map of water information that can be displayed in real time is displayed. On this basis, the "one library" of comprehensive informationization of water affairs from the state to the locality is organized; the different authorities are defined, and the "one platform" for the unified collection, exchange and application platform that provides information services support for the water operation management departments at all levels. Through continuous practice and exploration, the future smart water will have the characteristics of "more standardized, more intelligence, safer, more open and wider".

(1) More standardization: Establish an impeccable water policy and regulation system, formulate and improve key policies and regulations related to water supply, drainage, water conservation, and related implementation rules, so that the newly formulated tax policies and regulations can be implemented. At the same time, the formulation of standard norms should return to the ontology of Smart water research, adapt to the new requirements of cloud computing, big data and Internet of Things for the further development of Smart water services, and standardize the development and innovation of smart water services in the era of data cloud services.

(2) Safer: Establish a comprehensive enterprise network security protection system, which can effectively block attacks from external networks and intranets and ensure network operation security [15]. Cooperate with the comprehensive application of various security protection technologies and platforms, and comprehensively improve the management level of information security through the preparation and implementation of information security management regulations and various special security management specifications.

(3) More intelligent: Building a cloud-based big data analysis system [6], the cloud computing can perform high-speed operations and simulations for complex water cycles, water distribution and water regulation processes, through virtualization, distributed processing, and broadband networks. Technology enables Internet resources to be switched to the required applications at any time. Users can access the computer and storage system according to their personal needs in a "plug and play" way to achieve the required operations, and their powerful computing capabilities can be realized. Management decision models such as water resources scheduling, internal simulation, and pipe network pressure balance.

(4) More open: establish a more open public information platform, make full use of mobile terminals and communication technologies, let people know relevant information such as water stoppage and 
maintenance in the first time, and provide various channels to facilitate people to track developments. At the same time, through the mobile terminal or WeChat platform, the public's participation in smart water affairs will be improved, and relevant information on the spot will be provided in time to help enhance interaction and improve management.

(5) More extensive: In the future, smart water services will not only be limited to urban water supply and drainage systems. Today, when water resources are more and more precious, industrial enterprises with large water demand can also apply. It is imperative for industrial water users represented by thermal power plants to achieve water conservation and environmental protection through smart water system.

\section{Conclusion}

The party's 19th National Congress reported "promoting the deep integration of the Internet, big data, artificial intelligence and the real economy". Today, in the comprehensive construction of an "Intelligent society", smart water system construction is a response to this trend. At present, there is still a long way to go before smart water affairs can break through many bottlenecks such as policy system constraints, lack of standard norms, prominent information islands, difficult data operations, and lack of professional talents. The construction of smart water system can not only stay at the process of comprehensive perception and data collection. It should establish the core concept of data analysis and mining through the integration of software and hardware, and constantly improve the big data foundation and technology evaluation system. This requires the attention of industry regulatory authorities and the positive response of various water companies to jointly promote the development of smart water business.

\section{Acknowledgments}

This paper is supported by the Beijing 2018 Annual Mountain Flood Disaster Prevention Project - Monitoring and Early Warning Platform and Monographic Study;JZ0203112018.

\section{References}

1. Deren Li,Yuan Yao,Zhenfeng Shao,etc.From digital Earth to smart Earth [J]. Chinese Science Bulletin, 2014, 59(08):722-733.

2. Jiang Yunzhong, Ye Yuntao, Wang Hao. Smart basin and its prospects for application[J]. Systems Engineering-Theory \& Practice, 2011, 31(6):1174-1181.

3. Yang Mingxiang,Jiang Yunzhong,Tian Yu,etc.Demand analysis of smart water resource[J].Journal of Tsinghua University(Science and Technology),2014,54(01):133-136+144.

4. SUN Guoqing. Research and application on key technologies of smart water[J]. Water Resources
Informatization, 2018(1):46-49.

5. TIAN Yu, JIANG Yunzhong, YANG Mingxiang. Foundation and development strategy for wise water affair management[J]. China Water Resources, 2014(20):14-17.

6. 2017 China Smart Water Development White Paper [R]. Beijing: China Urban Water Supply and Drainage Association Science and Technology Committee, 2017.

7. White Paper on the Development of China's Smart Water Industry [R]. Beijing: China Electronics and Information Industry Development Research Institute, 2013.

8. China Municipal Public Network. Domestic wisdom water status and foreign wisdom water development trend \& case analysis [EB/OL].http://www.szgy.org/show_news.asp?id=7 908, 2017-10-26/2018-7-31

9. China Water Network. 20 smart water case details (on)

[EB/OL]. http://www.h2o-china.com/news/view?id=263 935\&page $=1,2017-9-19 / 2018-7-31$

10. China Water Network. 20 smart water case details (below)

[EB/OL].http://www.h2o-china.com/news/view?id= 264

135\&page $=1,2017-9-22 / 2018-7-31$

11. DongHaitian.Construction and analysis of key technologies "wisdom Water" platform system[J].Water Resources Planning and Design,2017(02):22-24.

12. Pan Hongtao. Urban Intelligent Water Big Data Business Application Architecture and Technology Discussion [A]. Hohai University, China Water Conservancy Society. Exploring "Smart Water Conservancy" to Promote Technological Innovation_-2017 (Fifth) China Water Conservancy Information Technology Forum Paper Set [C]. Hohai University, China Water Conservancy Society:, 2017: 8.

13. Sun Guoqing. Design and Implementation of Smart Water Platform Software Based on GIS[J].Internet of Things Technologies,2017,7(06):100-102.

14. Liu Baide.Summary of the construction standards and guidelines for smart water information systems[J].City and Town Water Supply,2016(06):10-15.

15. Li Yuting.Analysis on the Security Design of Smart Water Network[J].Shaanxi Water Resources,2018(03):248-249+252. 